\title{
DYNAMIC RELATIONSHIP OF STEEL PRICES BETWEEN TWO DIFFERENT MARKETS:TAIWAN AND MAINLAND CHINA
}

Yong-Huang Lin

Associate Professor, Department of Construction Engineering, National Taiwan University of Science and Technology, Sec. 4, Kee-lung Rd., Taipei, Taiwan, R.O.C.

Yun-Wu Wu

Associate Professor, Department of Architecture, China University of Technology, No. 56, Sec. 3, Sing-long Rd., Taipei, Taiwan 116, R.O.C., david11.wu@msa.hinet.net

Follow this and additional works at: https://jmstt.ntou.edu.tw/journal

Part of the Civil and Environmental Engineering Commons

\section{Recommended Citation}

Lin, Yong-Huang and Wu, Yun-Wu (2006) "DYNAMIC RELATIONSHIP OF STEEL PRICES BETWEEN TWO DIFFERENT MARKETS:TAIWAN AND MAINLAND CHINA," Journal of Marine Science and Technology. Vol. 14: Iss. 4, Article 7. DOI: $10.51400 / 2709-6998.2086$

Available at: https://jmstt.ntou.edu.tw/journal/vol14/iss4/7

This Research Article is brought to you for free and open access by Journal of Marine Science and Technology. It has been accepted for inclusion in Journal of Marine Science and Technology by an authorized editor of Journal of Marine Science and Technology. 


\title{
DYNAMIC RELATIONSHIP OF STEEL PRICES BETWEEN TWO DIFFERENT MARKETS: TAIWAN AND MAINLAND CHINA
}

\author{
Yong-Huang Lin* and Yun-Wu Wu**
}

Key words: steel price, co-integration, granger causality, China.

\section{ABSTRACT}

Price variation is one of the major factors taken into account in cost control decision in construction projects. Previous researches have focused on the short-term price prediction of a merchandise within a closed single market without considering the long-term effect by interacting with other markets. The econometric methods such as structural break test, co-integration analysis, and Granger causality test were used to examine the dynamic short-term and long-term relationships of steel prices between two different markets, Taiwan and China, over the period of $1995 \sim 2004$. The steel price of China was found to have the leading discovery function by the following evidence. The structure change of China steel market leads Taiwan steel market at least six months and these two markets are cointegrated into a long-term equilibrium relationship. In addition, a bidirectional causality exists between these two markets suggested by the results from Granger causality test.

\section{INTRODUCTION}

According to the Industrial Technology Intelligence Services [16] survey, China's raw steel consumption increased from 141 million tons in 2000 to 236 million tons in 2003, an average increase of $24.8 \%$ per year. Over the same period, the market price of steel in Taiwan increased 200\%, from approximately US $\$ 250$ per ton in 2000 to US\$550 per ton in 2003. Do these suggest that the changes in demand and price within these two markets can substantially affect each other?

Conventional reasons suggest that the high volatility of the steel price is the result of the relationship between market supply and demand. But economic globalization and the process of liberalization have

Paper Submitted 02/28/06, Accepted 04/24/06. Author for Correspondence: Yun-WuWu. E-mail: david11.wu@msa.hinet.net.

*Associate Professor, Department of Construction Engineering, National Taiwan University of Science and Technology, Sec. 4, Kee-lung Rd., Taipei, Taiwan, R.O.C.

**Associate Professor, Department of Architecture, China University of Technology, No. 56, Sec. 3, Sing-long Rd., Taipei, Taiwan 116, R.O.C. accelerated the integration of world markets in recent years.

Because the information of price movement in one market can transmit instantly to another market, world markets are dependent upon each other more than before. Under certain circumstances, one market may lead another. Therefore, understanding the dynamic price relationship between different markets and testing this relationship to see if it is a structure change of long-term trend or short-term shock plays an important role in making cost-control decisions in the construction industry. As mentioned above, if the steel price increases by $200 \%$ in Taiwan, it implies that the material cost has increased by $200 \%$ for the construction industry, especially during $2000 \sim 2003$. Thus, uncertainty is a characteristic of construction industry. Because of the long periods involved in construction, variations in the price of materials are the main factors influencing costs and profits of construction.

Accordingly, analysis of the long-term trend and variations in the price of materials does help improve the quality of decision making in the construction industry which is a major objective of construction management [2].

Past economic research in construction management has focused on the following:

In the United Kingdom, Akintoye \& Skitmore analyzed the accuracy of three different models: the tender price index (TPI) produced by the Building Cost Information Service (BCIS) system, the Davis, Langdon \& Everest System, and Akintoye \& Skitmore's reducedform simultaneous equation for forecasting movement in macro building prices [2]. But these three models do not consider the changes in external economic circumstances. For example, a severe economic recession will decrease the accuracy of forecasts made by these three models.

Fitzgerald and Akintoye [10] used a number of quantitative methods to assess the accuracy of TPI produced by experts for BCIS. These methods included mean error (ME), mean absolute error (MAE), meansquare error (MSE), root-mean-square error (RMSE), 
Theil U inequality coefficient (TUIC) ${ }^{1}$, and mean absolute percentage error (MAPE). Wang and Mei [27] used a time-series model, the Auto Regressive Integrated Moving Average (ARIMA) method to build a Taiwan Construction Cost Index (TCCI) model which forecasts the short-term construction cost indices in Taiwan. Then, Huang, Yang, and Wang [14] added a structural dummy variable to the existing TCCI model, which can increase the forecasting accuracy of the TCCI model.

The contributions of the above-mentioned past research focused mainly on short-term forecasting and different methods to improve forecasting accuracy. However, the methodologies used in the above studies limited them to an estimation of some short-term dynamic process only in one variable (the market itself), and do not allow testing and explaining the action of long-term equilibrium and the interrelationship between two variables (markets).

Hence, this study employs the techniques of cointegration analysis, structural change, vector error correction model (VECM) and Granger causality analysis to investigate the long-term equilibrium relationships between integrated variables, which were not shown in previous studies. This study has four purposes. Firstly, to use an extension of general equilibrium theory to explain the price variation from the market structure change of demand and supply between two markets. Secondly, to examine the long-term equilibrium relationship between China and Taiwan steel markets by cointegration analysis. Thirdly, to examine whether existing a structural change of steel price in China market or Taiwan market, empirical result finds that the occurrence of structural change in China leads Taiwan by half year. Fourth, to examine the short-term relationship between China and Taiwan markets using an error correction model and the Granger causality test.

The remainder of this paper is organized as follows. First, a theoretical foundation that underlies the subsequent empirical results will be provided. This will be followed by a description of the econometric method used in this study. Then, the data and empirical results will be presented. Lastly, conclusions will be summarized.

${ }^{1}$ Theil U inequality coefficient - this is UK construction tender price index forecasts

$$
U=\sqrt{\frac{(1 / n)^{*} \sum_{t=1}^{n}\left(e_{t}\right)^{2}}{(1 / n)^{*} \sum_{t=1}^{n}\left(A_{t}\right)^{2}}}
$$

$U$ attains its smallest value when forecasts are perfect and is in most cases confined to the closed interval between zero and unity (Theil, 1978).

\section{BACKGROUND}

As for the overall development and changes in price trends for the global steel market, at the beginning of the 1970s, monetary inflation and the bubble economy resulted in a rise in steel prices. The first energy crisis during $1973 \sim 1974$, along with the second energy crisis during $1979 \sim 1980$, caused the inflation that led to an increase in steel prices [15]. The subsequent Five Nations' Plaza Agreement caused the U.S. dollar to depreciate, and coupled with the initiation of the Japanese bubble economy, steel prices rose (Figure 1).

After the 1980 s, the variation in supply and demand led to the changes in steel material prices. Following the collapse of Soviet Union during 1990, the new CIS released a huge surplus of priced material into the world steel market, especially into the Asian region. This forced the global steel supply to far exceed the demand, making steel material prices all over the world slack to a low point.

After the Great Hanshin-Awaji Earthquake in 1995, the demand in steel usage increased to exceed the supply, causing steel prices to increase. With the occurrence of the Asian Financial Crisis in 1997 reduced the demand and caused steel prices to again fall [3].

China becomes the main driving force of growth in global steel price since 2002 [16]. This is "China Demand Effect". The main reason was the growth in China's dynamic economy (urbanization, the fast development in infrastructures, and to host the Olympics required the construction of enormous sports facilities). Therefore, China will be unable to produce sufficient amounts of steel to meet with the demand of highquality steel products in the market, and must rely on importation of partial steel materials from abroad [26].

China's fast economic development has caused the flow of raw materials into China from all over the world. Because of the nearby geographic location, the comparative advantage increases the steel materials exported from Taiwan to China year by year. It has changed the original state of material prices and supply and demand of the two markets. The mutual influences and price fluctuations between them are worthy for our research.

\section{EXPLANATION BASED ON ECONOMIC THEORY}

\section{The market function}

This study focuses on the steel market, as an example, to explain market function. Market function was always explained by a general equilibrium theory and presented in a demand-supply diagram as in Figure 


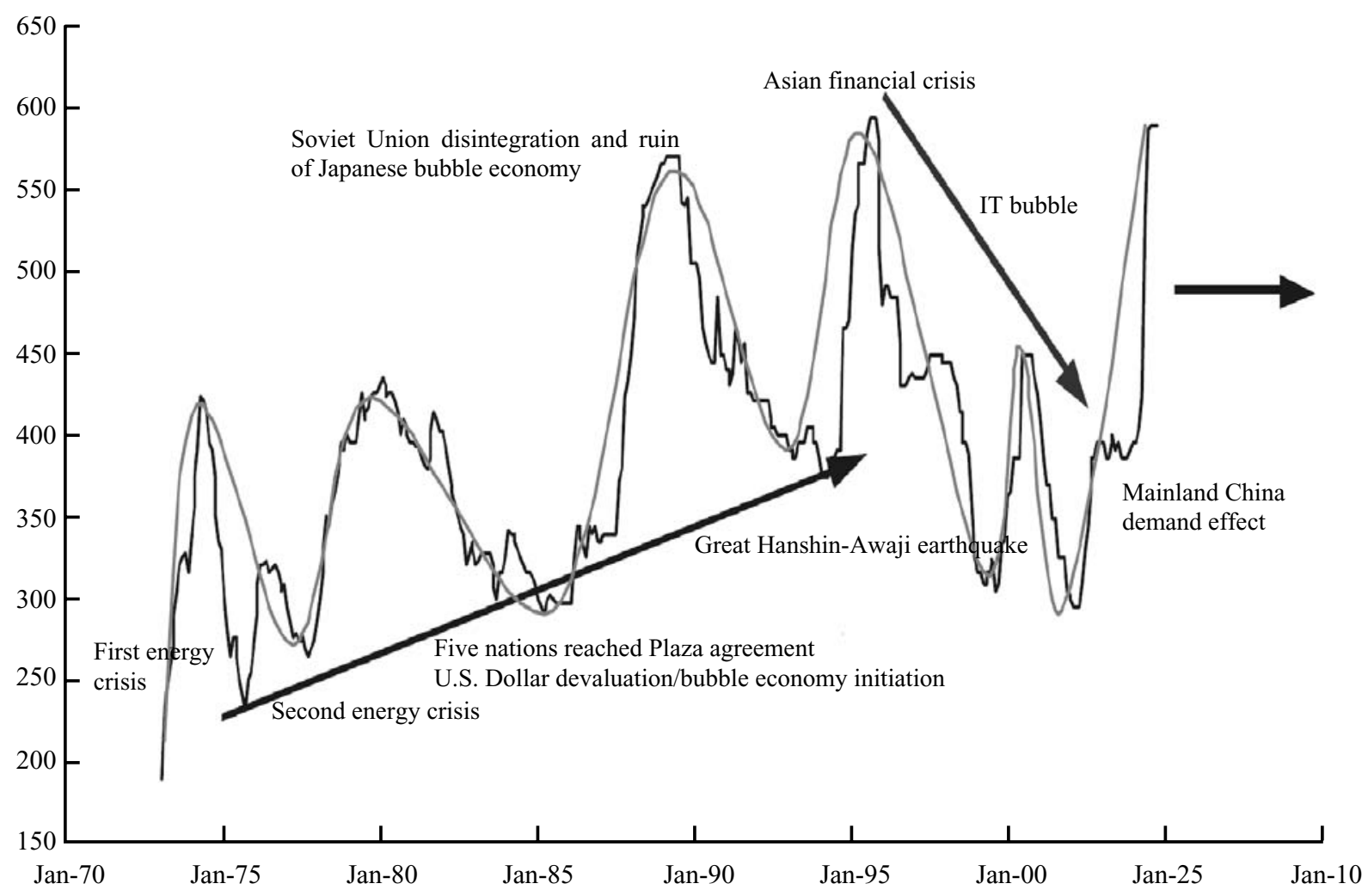

Fig. 1. The changes in price trends for the steel market [16].

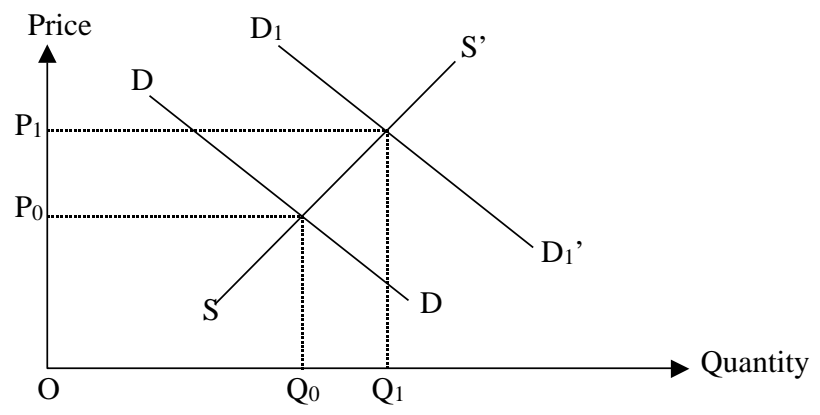

Fig. 2. Demand and supply diagram.

2. Suppose that the consumer demand of steel is changing, which causes the demand curve to shift to the right. This is illustrated in Figure 2, where the demand curve shifts from $\mathrm{DD}^{\prime}$ to $\mathrm{D}_{1} \mathrm{D}_{1}^{\prime}$. During the equilibrium situation, when $\mathrm{DD}^{\prime}$ is the demand curve, the equilibrium price is $\mathrm{OP}_{0}$. But when the demand curve shifts to $\mathrm{D}_{1} \mathrm{D}_{1}{ }^{\prime}$, a shortage of $\left(\mathrm{OQ}_{1}-\mathrm{OQ}_{0}\right)$ develops at this price. That is, the quantity demanded exceeds the quantity supplied at this price by $\left(\mathrm{OQ}_{1}-\mathrm{OQ}_{0}\right)$.

Consequently, suppliers raise their price. After market reactions and adjustments, the market will tend to settle at $\mathrm{OP}_{1}$, the new equilibrium price, and the quantity will tend to settle at $\mathrm{OQ}_{1}$.

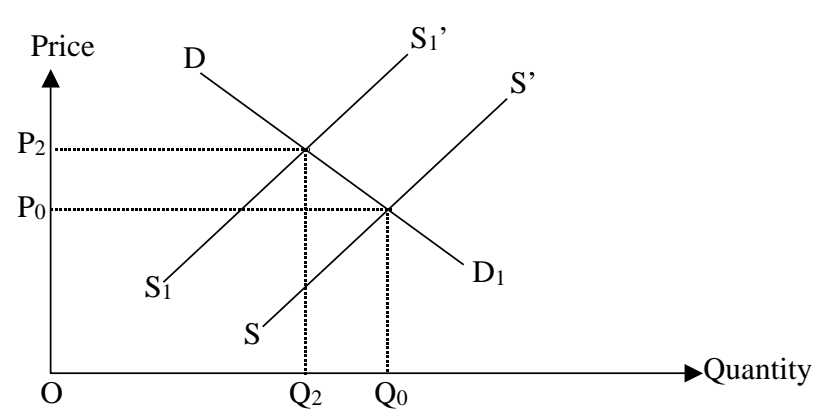

Fig. 3. Demand and supply diagram.

Supply curves, like demand curves, shift over time. What happens to the equilibrium price of steel when its supply curves shifts?

Suppose that the supply curve shifts from SS' to $\mathrm{S}_{1} \mathrm{~S}_{1}$ ' in Figure 3. What will the effect be on the equilibrium price? Obviously, it will increase from $\mathrm{OP}_{0}$ (where the SS' curve intersects the demand curve) to $\mathrm{OP}_{2}$ (where the $S_{1} S_{1}$ ' supply curve intersects the demand curve.)

\section{Market structure change}

Now, taking the steel markets of Taiwan and China 
as examples, we extend the general equilibrium theory from one market to explain the price interrelationship between the above two markets.

For China's steel market, when the quantity demand increased from 141 million tons in 2000 to 236 million tons in 2003, the demand curves turned to the right, shifting from DD' $\rightarrow D_{2} D_{2}{ }^{\prime} \rightarrow D_{3} D_{3}{ }^{\prime}$ (Figure 4)

By linking the theory discussed above, when the demand curve shifts, a shortage of $\Delta \mathrm{X}_{1}\left(=\mathrm{OQ}_{3}-\mathrm{OQ}_{0}\right)$ and $\Delta \mathrm{X}_{2}\left(=\mathrm{OQ}_{4}-\mathrm{OQ}_{3}\right)$ develops at the equilibrium price $\mathrm{OP}_{3}, \mathrm{OP}_{4}$ by $\Delta \mathrm{X}_{1}, \Delta \mathrm{X}_{2}$.

Through the marketing price adjustment process, suppliers will raise the price and will tend to settle at $\mathrm{OP}_{4}$ at $\mathrm{t}_{4}$. The final equilibrium price, and quantity will be settled at $\mathrm{OQ}_{4}$.

Now suppose there is a production deficiency in China, which makes the quantity to be imported from another country (e.g., Taiwan) equal to $\left(\mathrm{OQ}_{3}-\mathrm{OQ}_{0}\right)$ and $\left(\mathrm{OQ}_{4}-\mathrm{OQ}_{3}\right)$. When the steel price in China is higher enough to cover all the costs and generate profits, then, in this situation, what will happen in the Taiwan steel market? Suppose the demand of the Taiwan steel market remains constant as $\left(\mathrm{D}_{\mathrm{s}} \mathrm{D}_{\mathrm{s}}{ }^{\prime}\right)$. The exported quantity $\Delta \mathrm{X}_{1}, \Delta \mathrm{X}_{2}$ will cause the supply curve to shift to
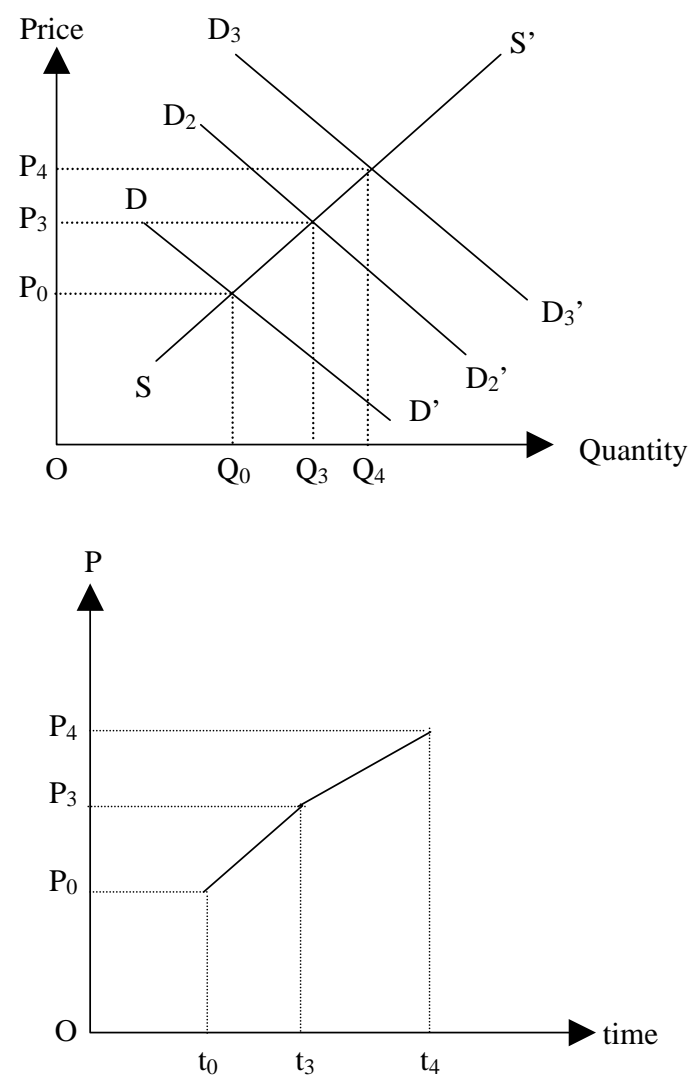

Fig. 4. The changing situation of demand and supply in Mainland China. the left. This is shown in Figure 5. Where the supply curve shifts from $\mathrm{SsSs}^{\prime} \rightarrow \mathrm{S}_{5} \mathrm{~S}_{5}{ }^{\prime} \rightarrow \mathrm{S}_{6} \mathrm{~S}_{6}{ }^{\prime}$ for the exported quantity of $\Delta X_{1}\left(=O Q_{0}{ }^{\prime}-O Q_{5}\right), \Delta X_{2}\left(=O Q_{5}-O Q_{6}\right)$.

The quantity of local supply will be reduced, which leads to market price adjustment. Suppliers will raise the price, which will tend to settle at $\mathrm{OP}_{6}$ at $\mathrm{t}_{6}$. The final equilibrium price, and quantity will be settled at $\mathrm{OQ}_{6}$. For this reason, the steel price went up from approximately US\$250 per ton in 2000 to US\$550 per ton 2003.

\section{Characteristic of the market structure change}

Shifts in China's demand not only cause its own steel price to vary, but these shifts also influence Taiwan's steel price. That is, there is an existing longterm equilibrium and a co-movement or lead-lag relationship between these two markets.

\section{DATA}

\section{Data source and processing}

The present study chooses China steel market and Taiwan steel market as the study subjects. It makes use of the econometric method through the theory of steel
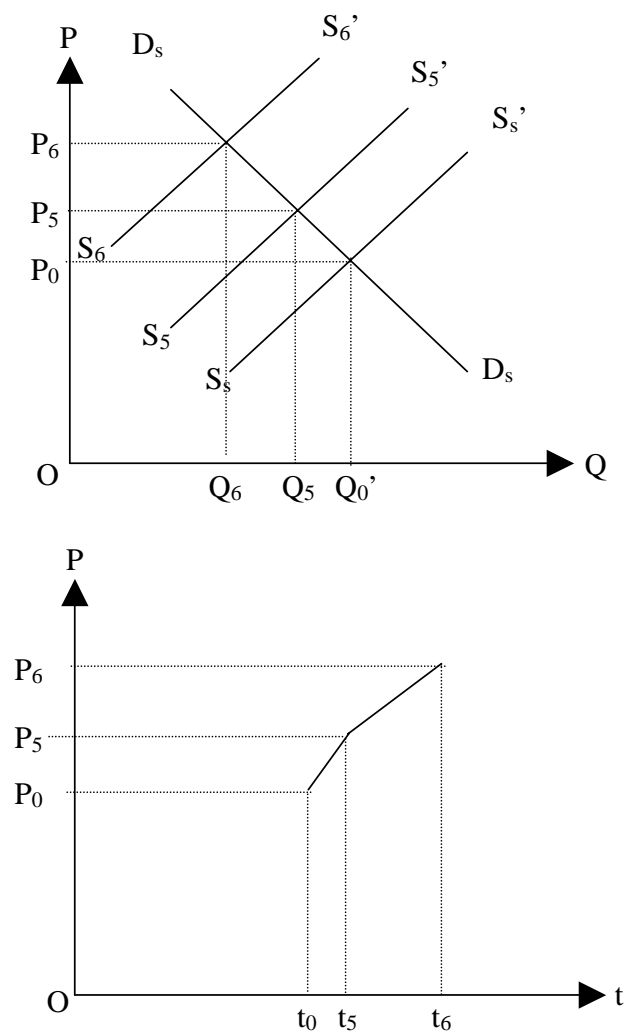

Fig. 5. The changing situation of demand and supply in Taiwan. 
market structural change to analyze the effects of demand and supply changes on steel prices in the two markets. To understand the market demand and supply changes, we must obtain the price time series of steel in the two major steel markets prior to further empirical examination.

\section{Data source}

This study compiles the data and information from Directorate-General of Budget, Accounting and Statistics, Executive Yuan, R.O.C. [9], the Taiwan Steel \& Iron Industries Association(www.mysteel.com) and from Metal Bulletin and then proceeds with the analysis.

\section{Data processing}

The time series data used by this study cover from April 1995 to February 2004. With monthly intervals, there are a total of 120 items of data points. The numerical value of data is assigned as the average of the highest and lowest prices, the units are in US dollars/ ton, and the year 2001 is used as the base year. That is, the mean of each month in 2001 is regarded as 100 and the index value of each month is equated as (the numerical value of each month/average value of the year 2001) $\times 100$. The index number of each year is calculated and the $\log$ of each index value is obtained before proceeding with empirical examination.

\section{Data analysis}

Figure 6 represents the moving trend of China and Taiwan's steel prices (the data are the results after conversion to a logarithmic scale). From 1995 to 1999 , both trends display a descending tendency. The steel price in China floated up and down from 1999 to June 2001 , but after the second half year of 2001, it began to

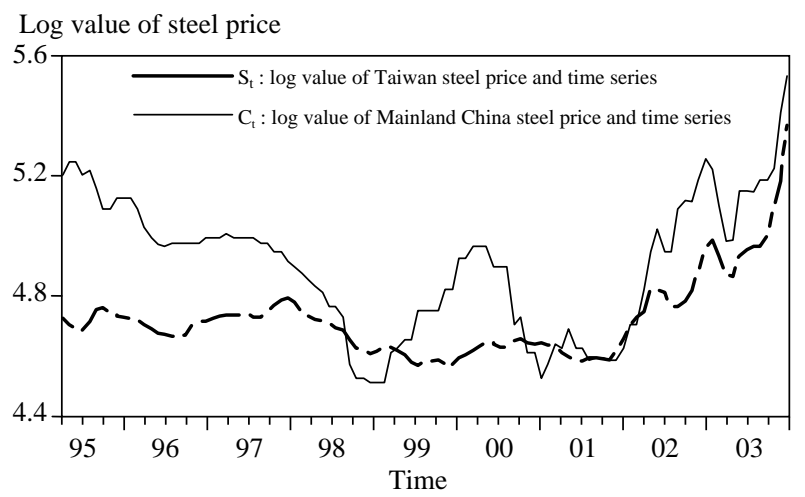

Fig. 6. Time series for $S_{t}$ and $C_{t}$. ascend dramatically. In 2002, the trend in Taiwan showed a rise as well. We infer that the rise of the steel price in China in 2001 was because of the success of China's application to host the Olympic game in July 2001 that, in turn, drove up the demand for domestic steel. After this period, Taiwan's steel price began to rise in 2002. This study aims to examine whether there is a correlation between the rise in China's steel price and that in Taiwan. In light of this, we carry out the Chow test for data from July 2001 to measure the structure changes involved.

\section{Structure change}

Because of success, in July 2001, of China's application to host the Olympic games, coupled with the economic development caused by liberalization, various civil and architectural projects unfolded in China, and China's steel demand increased from 141 million tons in 2000 to 236 million tons in 2003. At the same time, the price of steel in Taiwan went up to approximately US\$550 per ton in 2003 from US\$250 per ton in 2000. It is not unreasonable to infer that an interactive relationship between the steel price in China and that in Taiwan might incur from structure changes. Therefore, this study applies the Chow test $[5,6]$, initially to verify whether there is any structural change in the two market variables.

The empirical results reveal that there was structural change in China in April 2002 and its Chow test value is $12.48284(\mathrm{Pp}=0.000614)$. Structural change occurred in Taiwan in January 2003 with a Chow test value of $4.898189(\mathrm{Pp}=0.003250)$. In other words, the two variables produce structural changes at the $10 \%$ and $5 \%$ levels, respectively, and the China steel market appears to influence the Taiwan market within about half a year.

The basic statistical data analysis in Table 1 shows that the standard deviation of steel prices in Taiwan is

Table 1. Summary statistics for $C_{t}$ and $S_{t}$

\begin{tabular}{lllr}
\hline$C_{t}$ & & $S_{t}$ & \\
\hline Mean & 4.900676 & Mean & 4.719206 \\
Std. dev. & 0.226860 & Std. dev. & 0.134230 \\
Skewness & 0.041931 & Skewness & 1.934940 \\
Kurtosis & 2.361347 & Kurtosis & 8.268120 \\
Jarque-Bera & 1.849810 & Jarque-Bera & $190.5003^{* * *}$ \\
\hline
\end{tabular}

Note:

1. $C_{t}$ and $S_{t}$ are the symbols for the Mainland China steel price time series and Taiwan steel price time series.

2. *** denotes that at the $1 \%$ significance level, the null hypothesis is rejected. 
less than that of China. The reason likely is that the demand for steel in China increased in 2001, which caused larger statistical changes than in Taiwan. Examining both the skewness and kurtosis, data from Taiwan and China skew to the right (are positively skewed) and show a platykurtic (flat and diffuse) phenomenon. The p-value derived from the Jarque-Bera test indicates that the null hypothesis of normal distribution in Taiwan's steel prices should be rejected.

\section{ECONOMETRICS METHOD}

\section{Model setting}

This study applies the theory of co-integration to establish whether a long-term equilibrium relationship exists between Taiwan and China's steel markets. First, we apply the Augmented Dickey-Fuller (ADF) [7, 8, 24] and Phillips-Perron (PP) unit root test [23] to test whether or not the variables under study being studied are stationary. Then, a co-integration test is used to analyze whether a long-term and stable equilibrium relationship is present between the variables. Afterwards, Granger causality is used to test whether there is a lead-lag relationship between the variables. Finally, the error correction model is used to examin short-term equilibrium relationship. The econometrics method adopted by this study is illustrated as follows.

\section{Unit root test}

The primary purpose of the unit root test is to confirm that the integrated order of the variables and each time series of variables are stationary, in order for the co-integration analysis to proceed.

When the variables exhibit a non-stationary time series, there will be the problem of spurious regression during the analysis - the statistical t-test value and the coefficient of determination, value, are very high, whereas the Durbin-Watson (DW) value is very small. Thus, the relationship of the variables being studied will be incorrectly identified. If the variables are confirmed to be of a non-stationary time series, it is necessary to difference the series to transfer them into stationary before proceeding with the next step of the analysis.

This study adopts the Augmented Dickey-Fuller (ADF) test, and the method proposed by Phillip and Perron to proceed with the unit root test. This is explained as follows:

The Augment Dickey-Fuller (ADF) Unit Root Test method is extended from the DF test of Dickey and Fuller (DF) test [7]. The method of extension is to carry out the first order differencing of the tested variables, and the equation is,

$$
\Delta Y_{t}=\alpha+\beta Y_{t-1}+\sum_{i=1}^{p-1} \gamma \Delta Y_{t-1}+\theta_{t}+\varepsilon_{t}
$$

Where $Y_{t}$ is the variable, $\Delta=1-L$ denotes the difference operator, and $\varepsilon_{t}$ represents the white noise error term. Now, Eq. (1) is tested with a null hypothesis $H_{0} . H_{0}: Y_{t}$ represents non-stationary time series.

When the $\beta \mathrm{t}$-value is less than the statistic critical value, $H_{0}$ is rejected. As to the constant term, $\alpha$, and the trend term, $\theta_{t}$, they should be kept when the t-value is of significance.

The Phillips and Perron test for unit roots adopts the ADF- related hypothesis. However, to avoid the problem caused by the possible existence of error term in the time series during the ADF unit root test (due to the mis-specification of the dynamic structure of $Y_{t}$ ), the PP test for unit roots first calculates the ADF statistics and modifies them to PP statistical values (Phillips-type test) under the circumstance that the error term is allowed to be of weak dependency and heterogeneous variance.

In other words,

$$
\begin{aligned}
Z\left(\tau_{\mu}\right)= & \left(S_{u / S_{T l}}\right) \tau_{\mu}-\frac{1}{2}\left(S_{T l}^{2}-S_{u}^{2}\right) \\
& \cdot\left\{S_{T l}\left[T^{2} \sum_{t-2}^{T}\left(y_{t-1}-y_{-1}\right)^{2}\right\}^{1 / 2}\right.
\end{aligned}
$$

For the sake of discreetness, this study simultaneously employs the ADF and PP tests for unit roots in which the ADF test uses Akaike's information criterion (AIC) [1] to decide the latest lag period. When the $n$ value cannot be decided by AIC, the PP test for unit roots then will be used. The latest lag period of the PP test is automatically eliminated through selection by the Newey-West method [20]. And the test statistics are determined to be of unit root according to the Mackinnon critical value [19].

\section{Co-integration and error correction model}

In this study, co-integration analysis and the error correction model are used to test whether short-term and long-term equilibrium relationships exist between Taiwan's and China's steel markets. After confirming a unit root test, the long-term equilibrium relationship between Taiwan and China's steel markets is investigated using the following co-integration model. This model is the framework of a vector autogressive model by Johansen [17], and Johansen and Juselius [18]. 


$$
\begin{aligned}
X_{t} & =\sum_{i=1}^{p} X_{t-p}+U_{t}+\varepsilon_{t} \\
U_{t} & =\left[\begin{array}{c}
U_{s} \\
U_{c}
\end{array}\right] ; \varepsilon_{t}=\left[\begin{array}{c}
\varepsilon_{s, t} \\
\varepsilon_{c, t}
\end{array}\right] \sim N(0, \Sigma)
\end{aligned}
$$

Where $X_{t}=\left(S_{t}, C_{t}\right)^{\prime}$ is the vector of Taiwan and China's steel prices, each being integrated of order one (denoted I (1)). Assuming that the series are integrated by order zero (denoted I (0)) by taking first difference on the vector level, the model in vector error correction form is:

$$
\Delta X_{t}=\sum_{i=1}^{p-1} \Gamma_{i} \Delta X_{t-i}+\Pi X_{t-1}+U_{t}+\varepsilon_{t}
$$

Where $\Delta$ denotes the first difference operator; $\Gamma_{i}$ and $\Pi$ are $2 \times 2$ coefficient matrices measuring the short-term and long-term adjustments of the system to changes in $X_{t}$, and $U_{t}$ is a $2 \times 1$ vector of intercept, $\varepsilon_{t}$ is a $2 \times 1$ vector of white noise error terms.

$$
\Gamma_{i}=-\mathrm{I}+\mathrm{A}_{1}+\mathrm{A}_{2}+\ldots+\mathrm{A}_{i}
$$

For $\mathrm{i}=1,2, \ldots, \mathrm{p}-1$, and

$$
\Pi=-\left(\mathrm{I}-\mathrm{A}_{1}-\mathrm{A}_{2}-\ldots-\mathrm{A}_{p}\right)
$$

The $\Pi$ matrix provides information about the longterm relationship between variables $\left(S_{t}, C_{t}\right)$, and the rank of $\Pi$ is the number of linearly independent and stationary linear combinations of $\left(S_{t}, C_{t}\right)$.

Thus, testing for co-integration involves testing the rank of the $\Pi$ matrix, $r$, by examining whether the eigenvalues of $\Pi$ are significantly different from zero.

For testing the number of co-integrating vectors (or $r=$ the rank of $\Pi$ ), Johansen [17], Johansen and Juselius [18] proposed two statistics tests: the $\lambda_{\text {trace }}(r)$ test and the maximum eigenvalue $\left(\lambda_{\max }\right)$ test. The likelihood ratio for the trace test is

$$
\lambda_{\text {trance }}(r)=-2 \ln Q=-T \sum_{i=r+1}^{p} \ln \left(1-\hat{\lambda}_{i}\right)
$$

Where $\hat{\lambda}_{r+1}, \ldots \ldots, \hat{\lambda}_{p}$ are the smallest estimated $\mathrm{p}-\mathrm{r}$ eigenvalues. The null hypothesis to be tested is that there are, at most, $r$ co-integrating vectors. That is, the number of co-integrating vectors is $\leq \mathrm{r}$, when $\mathrm{r}$ is $0,1, \ldots$ The maximum eigenvalue test is represented as

$$
\lambda_{\max }(r, r+1)=-2 \ln Q=-T \ln \left(1-\hat{\lambda}_{r+1}\right)
$$

In this test, the null hypothesis of $\mathrm{r}$ co-integrating vectors is tested against the alternative of $r+1$ cointegrating vectors. Thus, the null hypothesis that $\mathrm{r}=0$ is tested against the alternative that $r=1$; that $r=1$ against the alternative that $\mathrm{r}=2$; and so forth. The cointegration tests are very sensitive to the choice of lag length. Here, the Akaike's information criterion (AIC) [1] and the likelihood ratio test are used to determine the length of lags required in the co-integration.

\section{Granger causality test}

According to the research of Granger [11] and Sims [25], the economic time series, $S_{t}$, is said to be "Granger Caused" by the time series $C_{t}$. The forecasting ability of the $S_{t}$ then can be improved with additional information from the past and present values of $C_{t}$. The general Granger causality test can be specified as follows:

$$
\begin{aligned}
& \Delta S_{t}=U_{s}+\sum_{i=1}^{p} \beta_{s, i} \Delta S_{t-i}+\sum_{i=1}^{p} \gamma_{s, i} \Delta C_{t-i}+\varepsilon_{s, t} \\
& \Delta C_{t}=U_{c}+\sum_{i=1}^{p} \beta_{c, i} \Delta C_{t-i}+\sum_{i=1}^{p} \gamma_{c, i} \Delta S_{t-i}+\varepsilon_{c, t}
\end{aligned}
$$

In Eq. (9), the Granger causality is examined by testing whether all $\gamma_{s, i}$ are equal to zero. Using a standard F-test of the null hypothesis by estimating the following restricted equation:

$$
S_{t}=U_{s}+\sum_{i=1}^{p} \beta_{s, t} \Delta S_{t-i}+e_{s, t}
$$

The respective sum of squared residuals is compared:

$$
R S S_{1}=\sum_{t=1}^{T} \widehat{\varepsilon}_{s, t}^{2} \quad R S S_{0}=\sum_{t=1}^{T} \hat{e}_{s, t}^{2}
$$

If the test statistic

$$
S_{1}=\frac{\left(R S S_{0}-R S S_{1}\right) / P}{R S S_{1 /(T-2 p-1)}} \sim F_{p, t-2 p-1}
$$

is greater than the specified critical value, then we reject the null hypothesis that $C_{t}$ does not Granger cause $S_{t}$.

In Eq. (10), the null hypothesis that $S_{t}$ does not Granger cause $C_{t}$ can be tested in an analogous way. If the causation cannot be rejected in both Eqs. (9) and (10), the variables must be considered interdependent (i.e. $C_{t}$ does Granger cause $S_{t}$, and $S_{t}$ does Granger cause $C_{t}$ in bi-directionally).

The following steps also are involved in our analysis. First, the existence of a stationary relationship between $S_{t}$ and $C_{t}$ prices is investigated in the VECM of Eq. (4) by using the $\lambda_{\max }$ and $\lambda_{\text {trace }}$ statistics [17] which test for the rank of $\Pi$. If $\operatorname{rank}(\Pi)=1$, then there is a single co-integrating vector and $\Pi$ can be factored as $\Pi$ 
Table 2. The results of various unit root tests

\begin{tabular}{llllll}
\hline & & $C_{t}$ & & $S_{t}$ \\
\hline ADF & Level & -0.828058 & $(1)$ & 1.854642 & $(1)$ \\
& First difference & $-7.746491^{* * *}$ & $(0)$ & $-3.194878^{* *}$ & $(1)$ \\
PP & Level & -0.199286 & $(0)$ & 1.677517 & $(2)$ \\
& First difference & $-7.746491^{* * *}$ & $(0)$ & $-5.946899^{* * *}$ & $(2)$ \\
NP & Level & -0.91135 & $(1)$ & 0.13842 & $(2)$ \\
& First difference & $-4.33306^{* * *}$ & $(0)$ & $-4.48034^{* * *}$ & $(2)$ \\
\hline
\end{tabular}

Notes:

1. $\mathrm{C}_{\mathrm{t}}$ and $\mathrm{S}_{\mathrm{t}}$ are the symbols for the Mainland China steel price time series and Taiwan steel price time series.

2. ** and $* * *$ denote significance at $5 \%$, and $1 \%$ levels, respectively.

3. The critical values for $1 \%, 5 \%$, and $10 \%$ levels of ADF, PP and NP, are $(-3.493747 ;-2.889200 ;-2.581596),(-3.493129$; $-2.888932 ;-2.581453)$ and (MZt: $-2.58 ;-1.98 ;-1.62)$, respectively. The critical values for the ADF t-statistics are from the [19] table.

4. The test statistic of the NP test is MZt.

5. The numbers in the parentheses of ADF, and NP are the appropriate lag lengths selected by MAIC (Modified Akaike information criterion) as suggested by [22], whereas the numbers in the parentheses of PP is the optimal bandwidths decided by the Bartlett kernel of [20].

$=\alpha \beta^{\prime}$, where $\alpha$ and $\beta^{\prime}$ are $2 \times 1$ vectors $^{2}$. Using this factorization, $\beta^{\prime}$ represents the vector of co-integrating parameters and $\alpha$ is the vector of error correction coefficients, measuring the speed of convergence of $C_{t}$ and $S_{t}$ toward a long-term steady state.

Second, if $S_{t}$ and $C_{t}$ prices are co-integrated, then causality must exist in at least one direction [12]. To formally test causality, the following expanded VECM may be estimated using OLS in each equation.

$$
\begin{aligned}
(1-L)\left[\begin{array}{l}
S_{t} \\
C_{t}
\end{array}\right] & =\left[\begin{array}{l}
U_{s} \\
U_{c}
\end{array}\right]+\sum_{i=1}^{p}(1-L)\left[\begin{array}{ll}
\beta_{s, i} & \gamma_{s, i} \\
\beta_{c, i} & \gamma_{c, i}
\end{array}\right]\left[\begin{array}{l}
S_{t-1} \\
C_{t-1}
\end{array}\right] \\
& +\left[\begin{array}{c}
\alpha_{S} \\
\alpha_{C}
\end{array}\right]\left[E C T_{t-1}\right]+\left[\begin{array}{c}
\varepsilon_{s, t} \\
\varepsilon_{c, t}
\end{array}\right]
\end{aligned}
$$

where $\Delta=1-\mathrm{L}$ is the difference operator $\beta_{S, i}, \gamma_{S, i}, \beta_{C, i}$, $\beta_{C, i}$ are the short-term coefficients and $E C T_{t-1}=\beta^{\prime} X_{t-1}$ is the error correction term from Eq. (13).

\section{EMPIRICAL RESULTS}

\section{Unit root test}

This paper conducts Augment Dickey Fuller Test [24], Philips-Perron Test [23] and Ng and Perron Test $[21,22]$ to find out the order of integration for Taiwan

\footnotetext{
${ }^{2}$ If $\operatorname{rank}(\Pi)=0, \Pi$ is a $2 \times 2$ null matrix and the VECM is reduced to a VAR model in first difference. If rank $(\Pi)=2$, then all variables in $X_{t-1}$ are I (0) and a VAR model in levels is estimated.
}

and China steel price time series. We conduct the tests in levels and then in first difference. Table 2 presents the results of the unit root tests for $S_{t}$ and $C_{t}$ variables. For China $\left(C_{t}\right)$ and Taiwan $\left(S_{t}\right)$, the absolute values of the test statistics are less than the critical values at conventional levels of significance. Both of these two series are non-stationary time series.

After first difference, the time series of $C_{t}$ rejects the unit root null hypothesis at the one percent level (ADF, PP and NP test), and St rejects the unit root null hypothesis at the one percent level (PP and NP test) and at the five percent level (ADF test). Taken together, these results confirm the findings from the ADF, PP, and NP tests that both the $C_{t}$ and $S_{t}$ series are nonstationary time series (that is I (1)).

Considering first difference, the null hypothesis of unit root, (i.e. I (0)) for both of these two time series is rejected, which means that both of these two series are stationary after first difference.

\section{Co-integration test}

This study uses the maximum likelihood method to verify the co-integration relationship between $C_{t}$ and $S_{t}$. Table 3 reveals that, at the significant level of 5\%, $\lambda_{\max }$ and $\lambda_{\text {trace }}$, statistical verification results suggest that from July, 1995 to February, 2004, the null hypothesis of $r=1$ in the model cannot be rejected. Thus, there is a co-integration relationship present between the steel price of $C_{t}$ and the steel price of $S_{t}$, with the cointegration equation as follows:

$$
S_{t-1}=1.625 C_{t-1}+C
$$


Table 3. Johansen co-integration tests of the co-integration rank for $C_{t}$ and $S_{t}$ during the entire period and segmented period

\begin{tabular}{lcccccrrr}
\hline & $\mathrm{H}_{0}=\mathrm{r}$ & $\mathrm{H}_{\mathrm{a}}=\mathrm{n}-\mathrm{r}$ & Eigen values & $\lambda_{\max }$ & $\lambda_{\text {trace }}$ & $\lambda_{\max }(0.95)$ & $\lambda_{\text {trace }}(0.95)$ \\
\hline \multirow{2}{*}{$1995 / 7$ to $2004 / 2$} & 0 & 1 & 0.083 & 9.06 & $15.92^{* *}$ & 14.07 & 15.41 \\
& 1 & 0 & 0.064 & $6.86^{* *}$ & $6.86^{* *}$ & 3.76 & 3.76 \\
$1995 / 7$ to $2002 / 4$ & 0 & 1 & 0.089 & 7.73 & 12.18 & 14.07 & 15.41 \\
$2002 / 5$ to $2004 / 2$ & 1 & 0 & 0.053 & $4.45^{* *}$ & $4.45^{* *}$ & 3.76 & 3.76 \\
& 1 & 1 & 0.569 & $18.55^{* *}$ & $20.68^{* *}$ & 14.07 & 15.41 \\
\hline
\end{tabular}

Notes:

1. According to structure break test and prior and after the success in mainland china's application of hosting olympic games, two segmented periods, $1995 / 07$ to $2002 / 04$, and 2002/05 to 2004/02 are divided for co-integration analysis. Then, cointegration analysis is carried out for the entire period from 1995/07 to 2004/02.

2. For null hypothesis, $\mathrm{H}_{0}$ : when $\mathrm{r}=0$, the test values of $\lambda_{\max }(0.95)$ and $\lambda_{\text {trace }}(0.95)$ are $(14.07 ; 15.41)$; when $\mathrm{H}_{0}: \mathrm{r}=1$, the test values of $\lambda_{\max }(0.95)$ and $\lambda_{\text {trace }}(0.95)$ are $(3.76 ; 3.76)$.

3. ** denotes that when the test value is at the significant level of $5 \%$, null hypothesis is rejected.

4. VAR lag length is 2 for models, 1995/7 to 2004/2, 1995/7 2002/04; VAR lag length is 3 for models 2002/5 to 2004/2.

This co-integration equation indicates that when China's steel price changes by one unit, Taiwan's steel price market will be affected and will change by 1.625 units. The two coefficient signs match with the theoretical expectations. Therefore, in the long term, the changes in the two market prices will show co-movement. That is, the two prices have a specific relationship of longterm equilibrium relationship.

China's 2001 success in applying to host the Olympic games drove a series of large increases in the demand and supply market of China's steel products. Prior to 2002, China was a self-enclosed, controlled market with little liquidity. Thus, its influence on steel price was only restricted by the inland Chinese market, which had a comparatively weaker effect on Taiwan's prices. The statistic results of $\lambda_{\max }$ and $\lambda_{\text {trace }}$ in Table 3 show that there is no long-term equilibrium between the Taiwan steel market and China steel market from July, 1995 to April, 2002, and that the corresponding cointegration equation is as follows:

$$
S_{t-1}=1.057 C_{t-1}+C
$$

The coefficient of $C_{t-1}$ suggests that, when China's steel price changes by one unit, Taiwan's steel price market will be affected with a change of 1.057 units in the same direction (a positive change). No significant effect was present as compared with $1995.07 \sim 2004.02$, which suggests that there was no consistent fluctuation or causal relationship during this period.

The liberalization of world trade and the opening of China's market, as well as its success of becoming the host of the Olympic Game in 2001, caused enormous construction projects to begin undertaken in China. The corresponding increase in demand of steel products produced an effect on Taiwan. The co-integration effects of $\lambda_{\max }$ and $\lambda_{\text {trace }}$ from $2002.5 \sim 2004.2$ demonstrate a long-term equilibrium relationship between the two countries with a co-integration equation as follows:

$$
S_{t-1}=1.484 C_{t-1}+C
$$

The coefficient value of $C_{t-1}$ is 1.484 which is larger than the coefficient value of $C_{t-1}=1.057$ during $1995.7 \sim 2002.04$. This suggests an obviously larger effect on Taiwan's steel market. This is because, after its success in becoming the host of the Olympic Game, China's steel demand increased a great deal, such that steel needed to be imported from foreign countries.

\section{Dynamic process -error correction model}

Eqs. (14) (15), and (16) reveal that the co-integration coefficients of $C_{t}$ and $S_{t}$ during the entire period and two segmented periods are 1.625, 1.057, and 1.484, which are all positive values. This means that $C_{t}$ and $S_{t}$ has a long-term, positive relationship. From the error correction term of $E C T_{t-1}$ in Table 4, we see that, when the two variables are adjusted toward a long-term trend, the $\alpha_{s}$ value is $-0.011,-0.008$, and -0.008 , adjusted downward, and the $\alpha_{c}$ value is $0.038,0.064$, and 0.274 , adjusted upward. This indicates that, when news produce short-term fluctuations, the reaction of $S_{t}$ is considerably obvious, which requires a downward adjustment to return to its long-term trend. $C_{t}$ is exactly the opposite, an upward adjustment takes it back to the long-term equilibrium state. Furthermore, for the coefficient estimates of $C_{t(-1)}$ and $C_{t(-2)}$ in the $\Delta S_{t}$ equation 
Table 4. The estimation results of the error correction model during different

Segmented periods

Error correction model

$(1-L)\left[\begin{array}{l}S_{t} \\ C_{t}\end{array}\right]=\left[\begin{array}{l}U_{s} \\ U_{c}\end{array}\right]+\sum_{i=1}^{p}(1-L)\left[\begin{array}{ll}\beta_{s, i} & \gamma_{s, i} \\ \beta_{c, i} & \gamma_{c, i}\end{array}\right]\left[\begin{array}{c}S_{t-1} \\ C_{t-1}\end{array}\right]+\left[\begin{array}{c}\alpha_{S} \\ \alpha_{C}\end{array}\right]\left[E C T_{t-1}\right]+\left[\begin{array}{c}\varepsilon_{s, t} \\ \varepsilon_{c, t}\end{array}\right]$

\begin{tabular}{lcccccc}
\hline & $\Delta \mathrm{S}_{\mathrm{t}}$ & & \multicolumn{5}{c}{$\Delta \mathrm{C}_{\mathrm{t}}$} \\
& $1995.07 \sim 2004.02$ & $1995.07 \sim 2002.04$ & $2002.05 \sim 2004.02$ & $1995.07 \sim 2004.02$ & $1995.07 \sim 2002.04$ & $2002.05 \sim 2004.02$ \\
\hline \multirow{2}{*}{$E C T_{\mathrm{t}-1}$} & -0.011 & -0.008 & -0.008 & 0.038 & $0.064 * *$ & $0.274 * * *$ \\
& $(-1.294)$ & $(-1.097)$ & $(-0.125)$ & $(1.833)$ & $(2.243)$ & $(3.112)$ \\
\hline \multirow{2}{*}{$\mathrm{C}_{\mathrm{t}(-1)}$} & $0.109 * *$ & 0.044 & 0.155 & 0.141 & 0.058 & 0.194 \\
& $(2.467)$ & $(1.604)$ & $(0.904)$ & $(1.300)$ & $(0.546)$ & $(0.916)$ \\
$\mathrm{C}_{\mathrm{t}(-2)}$ & -0.079 & 0.011 & $-0.367 * *$ & 0.067 & $0.348 * * *$ & $-0.600^{* * *}$ \\
\hline \multirow{2}{*}{$\mathrm{S}_{\mathrm{t}(-1)}$} & $(-1.753)$ & $(0.388)$ & $(-2.194)$ & $(0.606)$ & $(3.194)$ & $(-2.897)$ \\
& $0.807 * * *$ & $0.860^{* * *}$ & 0.660 & $0.812^{* * * *}$ & -0.115 & $1.302^{* * *}$ \\
$\mathrm{~S}_{\mathrm{t}(-2)}$ & $(6.658)$ & $(8.119)$ & $(1.897)$ & $(2.731)$ & $(-0.28)$ & $(3.024)$ \\
\hline \multirow{2}{*}{$\mathrm{U}$} & -0.195 & $-0.39 * * *$ & 0.252 & -0.495 & 0.354 & -0.446 \\
& $(-1.655)$ & $(-3.67)$ & $(0.611)$ & $(-1.712)$ & $(0.859)$ & $(-0.873)$ \\
\hline & 0.003 & 0.0007 & 0.019 & 0.001 & -0.004 & 0.029 \\
& $(1.483)$ & $(0.555)$ & $(1.539)$ & $(0.092)$ & $(-0.706)$ & $(1.879)$ \\
\hline
\end{tabular}

Note:

1. $\mathrm{C}_{\mathrm{t}}$ and $\mathrm{S}_{\mathrm{t}}$ are the symbols for the Mainland China steel price time series and Taiwan steel price time series.

2. $\mathrm{t}$ values are included in ( ).

3. ** denotes significance at the $5 \%$ significant level (The critical value for $5 \%$ is 1.980 ).

4. *** denotes significance at the $1 \%$ significant level (The critical value for $1 \%$ is 2.617 ).

and $S_{t(-1)}$ and $S_{t(-2)}$ in the $\Delta C_{t}$ equation, the positive and negative signs (+ and - signs) of $C_{t(-1)}$ and $S_{t(-1)}$ during other periods all are the same, except that the years from $1995.07 \sim 2002.04$ are different. This shows that the two variables, $C_{t}$ and $S_{t}$, have a positive relationship.

\section{Granger causality test}

As Granger [13] points out, if there exists a cointegration vector between $C_{t}$ and $S_{t}$, there is a causality relationship between these variables in one or both directions. A multivariate Granger casual model was applied to test the casual relationship between $C_{t}$ and $S_{t}$ (as indicated in Eqs. (9-11), and (12).

The null hypotheses are:

$H_{0}: C_{t}$ does not Granger cause $S_{t}$ (Eq. 9)

$H_{0}{ }^{\prime}: S_{t}$ does not Granger cause $C_{t}$ (Eq. 10)

Table 5 examines short-term Granger causality test within Eqs. (9) and (10). The F-test of explanatory variables indicates the significance of the short-term causal effects. The results suggest that, in the shortterm, there is bi-directional Granger causality between $C_{t}$ and $S_{t}$. This finding matches with the hypothesis proposed in this study.
Table 5. Result of the granger causality test during the time period $1995.7 \sim 2004.2$

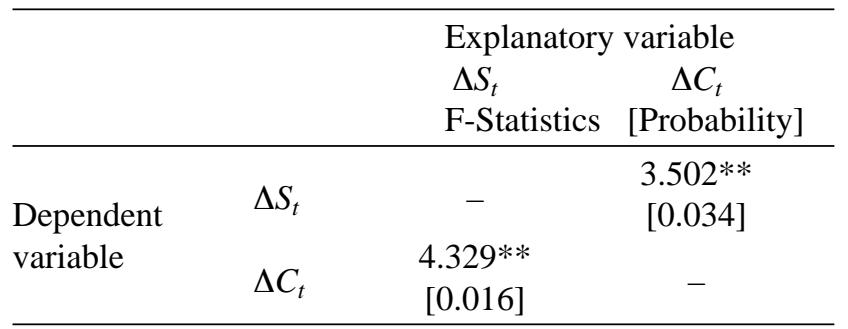

Note:

1. $\mathrm{C}_{\mathrm{t}}$ and $\mathrm{S}_{\mathrm{t}}$ are the symbols for the mainland china steel price time series and taiwan steel price time series.

2 . $* *$ denotes that at the $5 \%$ significant level, the null hypothesis $H_{0}$ is rejected.

\section{DISSCUSSION}

The aforementioned theory and empirical results demonstrate that China and Taiwan's steel markets have a long-term, equilibrium co-integration relationship and a lead-lag Granger causality relationship from 
July 1995 to February 2004. We can see that, when the demand for steel raises in China, during this information transmission process, construction firms (consumers) and the government can use this information to execute the following decisions such as raising tariffs, pursuing antidumping measures to prevent excessive price fluctuations in steel market. Furthermore, construction firms can preorder or postpone the purchase of materials to preempt profit loss resulting from price fluctuations.

The survey results indicated that the price of steel in Taiwan decreased from approximately US $\$ 580$ per ton in April 2005 to US $\$ 480$ per ton in August 2005 [4]. If relevant, organizational units can adopt corresponding measures and relevant countermeasures in advance, in accordance with the findings presented by this study; then they can prevent overstock and monetary business losses from happening.

One of the limitations of the present study is that it only considers the casual relationship between the Taiwan and China steel markets in a bi-variate manner. Future research can incorporate more countries as variables, such as, the U.S.A., Japan, Russia, and members of the European Union. The research can also might consider and examine the effects of additional factors, including market scale, distance (transportation costs) and the existence of government policy interventions, on each variable. Our study findings can further be used as a basis of reference in future decision making.

\section{CONCLUSIONS}

The change in the price of steel is an important decision factor related to cost control in the construction industry. Taking this into consideration, this study makes use of co-integration analysis, an error-correction model, and the Granger causality test to examine the short-term and long-term dynamic price relationships between the Taiwan and China's steel markets. The research period (from April 1995 to February 2004) was segmented into two periods, April 1995 to April 2002 and May 2002 to February 2004(before and after the success in China's Olympic game application), for empirical analysis.

Important findings obtained include the following:

1. The co-integration test demonstrated that the interactions between the two markets exhibits the existence of a co-integration relationship during the entire period; but after the period is divided into two periods, there is a co-integration relationship from 2002.05 to 2004.02.

2. Empirical results suggest that, prior to 2002, Taiwan's steel market was not affected by China's steel market.
In other words, the two markets do not have a longterm equilibrium relationship.

This empirical analysis result confirms with the situation in reality. China and Taiwan had always been in the state of had two self-enclosed markets prior to 2002. Since the circulation and opening trade only just started, there were no significant interactive effects between these two markets prior to that period.

However, from the year 2002 on, global economic liberalization has affected China. Its entry into WTO and its 2001 success in its Olympic game application have resulted in international raw materials to being exported to China. Taiwan has experienced a similar effect. This matches with the empirical results of the present study, indicating that China and Taiwan's steel markets started to have a mutual, long-term equilibrium relationship starting in April 2002.

In addition, this study makes use of the Chow test to analyze whether structural change or merely shortterm shock existed between China and Taiwan's steel markets. Empirical results show that Mainland China's steel market has produced structural change in April 2002 with a Chow test value of 12.482 . There also was structural change in Taiwan's steel market in January 2003 with a Chow test value of 4.898. China's steel market leads the Taiwan market by approximately half a year. The Granger causality test then was carried out and the same conclusion was obtained.

\section{REFERENCES}

1. Akaike, H., "A new Look at the Statistical Model Identification," IEEE Transactions on Automatic Control, Vol. 19, pp. 716-723 (1974).

2. Akintoye, S.A. and Skitmore, R.M., "A Comparative Analysis of the Three Macro Price Forecasting Models," Construction Management and Economics, Vol. 12, No. 3, pp. 257-270 (1993).

3. Akio Noguchi, "World Steel Industry from Financial Crisis," Steel Times International, Vol. 22, No. 6, p. 16 (1998).

4. Chen, J.R., Looking at the Steel Price Trend Starting from the Second Half of the Year of 2005 from the Recent Development of the Steel Market (ITIS Project), Metal Industries R\&D Center, Taiwan (2005).

5. Chow, G.C., "Tests of Equality between Sets of Coefficients in Two Linear Regressions," Econometrica, Vol. 28, pp. 591-605 (1960).

6. Chow, G.C., Econometric Methods, McGraw-Hill, New York (1983).

7. Dickey, D.A. and Fuller, W.A., "Distribution of the Estimators for Autoregressive Time Series with a Unit Root," Journal of American Statistical Association, Vol. 74, pp. 427-431 (1979). 
8. Dickey, D.A. and Fuller, W.A., "Likelihood Ratio Statistics for Autoregressive Time Series with a Unit Root," Econometrica, Vol. 49, pp. 1057-1072 (1981).

9. Executive Yuan, R.O.C., Directorate-General of Budget, Accounting and Statistics (2005). from http://www.dgbas.gov.tw/

10. Fitzgerald, E. and Akintoye, A., "The Accuracy and Optimal Linear Correction of UK Construction Tender Price Index Forecasts," Construction Management and Economics, Vol. 13, No. 6, pp. 493-450 (1995).

11. Granger, C.W.J., "Investigating Causal Relations by Econometric Models and Cross-Spectral Methods," Econometrica, Vol. 37, pp. 424-438 (1969).

12. Granger, C.W.J., "Developments in the Study of Cointegrated Economic Variables," Oxford Bulletin of Economics and Statistics, Vol. 48, pp. 213-228 (1986).

13. Granger, C.W.J., "Some Recent Development in a Concept for Causality," Journal of Econometrics, Vol. 39, pp. 199-211 (1988).

14. Huang, Y.C., Yang, H.A., and Wang, C.H., "Increasing Forecast Accuracy of Taiwan Construction Cost Indices by Structural Dummy Variable," Journal of the Chinese Insititute of Civil and Hydraulic Engineering, Vol. 14, No. 4, pp. 651-658 (2002).

15. Haflich, F., "Energy Crisis Mauling West Coast Steel Mills," American Metal Market (2001).

from http://www.findarticle.com/p/articles/mi_m3MKT/ is_7_109/ai_69279648)

16. Industrial Technology Intelligence Services, 2004 Taiwan Industrial Outlook, Department of Industrial Technology, Ministry of Economic Affairs, Taipei, pp. 245-264 (2004).

17. Johansen, S., "Statistical Analysis of Cointegration Vectors," Journal of Economic Dynamics and Control, Vol. 12, pp. 231-254 (1988).

18. Johansen, S. and Juselius, K., "Maximum Likelihood
Estimation and Inference on Cointegration - with Applications to the Demand for Money," Oxford Bulletin of Economics and Statistics, Vol. 52, pp. 168-210 (1990).

19. Mackinnon, J.G., "Approximate Asymptotic Distribution Functions for Unit Root and Cointegration Test," Journal of Business and Economic Statistics, Vol. 12, pp. 164-176 (1994).

20. Newey, W.K. and West, K.D., "A Simple, Positive Semidefinite Heteroskedasticity and Autocorrelation Consistent Covariance Matrmix," Econometrica, Vol. 3, pp. 703-708 (1987).

21. Ng, S. and Perron, P., "Unit Root Tests in Arma Models with Data-Deoendent Methods for the Selection of the Truncation Lag," Jounral of the American Statistical Association, Vol. 90, pp. 268-281 (1995).

22. Ng, S. and Perron, P., "Lag Length Selection and the Construction of Unit Root Tests with Good Size and Power," Econometrica, Vol. 69, pp. 1519-1554 (2001).

23. Phillips, P.C. and Perron, P., "Testing for a Unit Root in Tome Series Regression," Biometrika, Vol. 75, pp. 335346 (1988).

24. Said, S.E. and Dickey, D.A., "Testing for Unit Roots in Autoregressive-Moving Average Models of Unknown Order," Biometrika, Vol. 71, pp. 599-607 (1984).

25. Sims, C.A., "Money, Income, and Causality," American Economic Review, Vol. 62, No. 4, pp. 540-552 (1972).

26. Uwe, P., "Steel Market in China: Constraints Check More Powerful Growth China Special," Deutsche Bank Research (2004). from http://www.dbresearch.com

27. Wang, C.H. and Mei, Y.H., "Model for Forecasting Construction Cost Indices in Taiwan," Construction Management and Economics, Vol. 16, pp. 147-157 (1998). 